\title{
Geoscience education using a brand-new Google Earth
}

\author{
TAKASHI SAWAGUCHI \\ Natural Science Laboratory, Toyo University \\ 5-28-20, Hakusan, BunkYoku-Ku, Tokyo 112-8606, JAPAN \\ E-MAILS: TSAwa@TOYO.JP
}

Abstract: A brand-new browser-based Google Earth version 9.0 has been released in April 2017. This paper presents pedagogical ideas for geoscience education using Google Earth. Several KML files representing geospatial data and images are compiled into a downloadable file. Students can learn geoscience subjects through step-by-step interactive activities as they observe various geological and geographical information such as topography, bathymetry, volcanoes, ocean floor age, gravity anomaly and so on.

\section{Manuscript:}

Received: Quadrennial Conference of the International Geoscience Education Organization Accepted: 14/01/2018

Citation: Sawaguchi T. 2018. Geoscience education using a brand-new google earth. Terræ Didatica, 14(4):415-416. URL: http://www.ige.unicamp.br/terraedidatica/.

Keywords: Google Earth, Geoscience Education, KML, geospatial data

Thematic line: Technology and Educational Innovation

\section{Introduction}

The "Google Earth" was firstly released in 2005, after Google acquired originally developed "EarthViewer" by Keyhole, Inc.. Google Earth run on multi-platform environments including Windows, Macintosh and Linux. "Google Earth for iPhone" has been available since 2008 soon after the release of iPhone in 2007, and Android OS version since 2010. Although Google Earth API allowed a web browser include Google Earth into web pages supporting additional geospatial data on the virtual Earth, Google announced that they had deprecated Google Earth API development in January 2017. Instead of the older versions of Google Earth, a brand-new browser-based Google Earth (version 9.0) has been released in April 2017.

Online contents of "Teaching with Google Earth" were published by Richard (2014) in "Teach the Earth - the portal for Earth Education". De Paor (2016) compiled three-dimensional virtual rocks on Google Earth for a virtual field tour or distanced learning.

In this presentation, I would like to introduce a geoscience education and pedagogical ideas using a brand-new Google Earth.

\section{Geospatial data on the brand-new Google Earth}

Google Earth version 9 is implemented by WebGL technology which enables rendering of interactive 3D graphic models on the modern web browsers without the use of any plug-ins, running on the Google Chrome browser. Three-dimensional topographical terrain and bathymetry are precisely reproduced on the virtual Earth. Standard KML files used in the older versions, which users can create, download and upload the customized layers on the Google Earth, are also validated in the new version. Here I have compiled nine useful KML layers published by various organizations as listed below for pedagogical usage in geoscience education.

- Hypocenters (USGS)

- Plate boundaries (USGS)

- Active volcanoes (Smithsonian Institution)

- Bathymetry (NASA, GEBCO)

- Topography (NASA, SRTM)

- Crustal thickness (CRUST1.0)

- Hotspots

- Age of ocean floor (Müller et al., 2008)

- Global gravity anomaly (UCSD)

Users can switch over visible/invisible of each layer respectively.

\section{Pedagogical idea}

\subsection{Volcanology and hot spot theory}

1. Show "Active volcano (Holocene)" layer to confirm distribution of volcanoes on the Earth.

2. Fly over the typical volcanoes to recognize the 


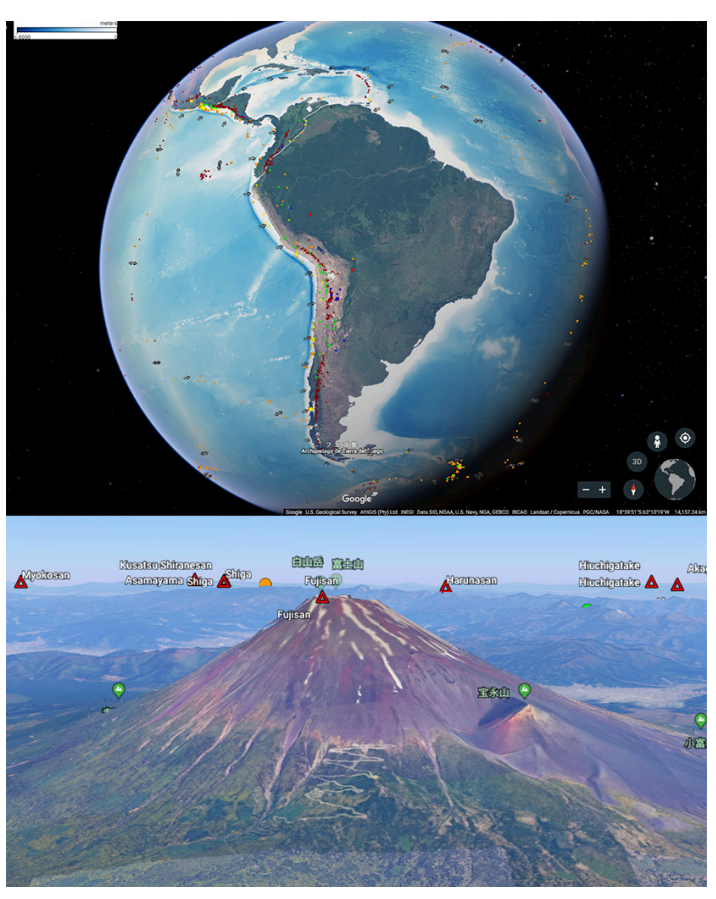

Figure 1. A brand-new Google Earth 9.0

characteristic shape of mountain slope (e.g. Stratovoncano at Mt. Fuji in Japan, shield volcano of Mauna Loa in Hawaii etc.) .

3. Fly over calderas (crater lakes). (e.g. Lake Toba in Indonesia, Yellowstone caldera in the Western U.S. etc.

4. Show "Plate boundaries" layer to discuss the location of volcanoes and plate boundaries.

5. Show "Hotspot" layer and search sea mountain chains which align from the hotspot region. Both "Plate boundaries" layer that indicates the plate motion and "Age of Ocean Floor" layer help understanding of hot spot trails.

\subsection{World Topography and Orogenic belts}

1. Show "Topography (SRTM)" layer to find high elevation regions on the Earth.

2. Show "Active volcano (Holocene)" layer to distinguish high mountain regions composed of volcanoes from others.

3. Show "Plate Boundaries" layer to recognize high mountain ranges by collision of continental crusts along convergent plate boundaries.

4. Find the another remaining high regions except two regions mentioned above (e.g Appalachian or Caledonian mountains as older orogenic belts).
5. Notice that average elevation of Antarctica and Greenland are high as thick ice sheets cover on those continents.

6. Comparing "Topography (SRTM)", "Bathymetry (GEBCO)", "Crustal thickness (CRUST1.0)" and "Global gravity anomaly (UCSD" to discuss the elevation of the Earth's surface and isostatic relationship.

\section{Conclusion}

With a brand-new Google Earth, students can overview the various geospatial data and easily access to both geological and geographical features modelled on the virtual Earth. Multi-touch devices also help students recognize the geological processes through interactive way and discuss with other students in a classroom. Furthermore we can make a guided virtual tours using a newly added "Voyager" features on Google Earth 9. A new technology will have an advantage in Geoscience education.

\section{References}

CRUST1.0. A new Global Crustal Model at 1x1 Degrees. URL: $\quad$ https://igppweb.ucsd.edu/ gabi/crust1. html

De Paor D. G. 2016. Virtual Rocks. GSA Today, 26(8). DOI: $10.1130 /$ GSATG257A.1.

GEBCO. General Bathymetric Chart of Oceans. URL: https://www.gebco.net

Hotspot coordinates exported as KML. URL: https:// en.wikipedia.org/wiki/Hotspot_(geology)

Müller R.D., Sdrolias M., Gaina C., Roest W.R. 2008. Age, spreading rates and spreading symmetry of the world's ocean crust, Geochem. Geophys. Geosyst., 9:Q04006. DOI:10.1029/2007GC001743.

NASA Earth Observations. Bathymetry (GEBCO). URL: https://neo.sci.gsfc.nasa.gov/view. php?datasetId=GEBCO_BATHY

NASA Earth Observations. Topography (SRTM). URL: $\quad$ https://neo.sci.gsfc.nasa.gov/view. php?datasetId=SRTM_RAMP2_TOPO

Richard G.A. 2014. Teaching with Google Earth. URL: http://serc.carleton.edu/introgeo/interactive/examples/morrisonpuzzle.html

Smithsonian Institution National Museum of Natural History. Global Volcanism Program. Holocene Volcanoes. URL: http://volcano.si.edu/ge/GVPWorldVolcanoes.kml

USDS. University of California. San Diego. Exploring Ocean Tectonics from Space. URL: topex.ucsd.edu/ grav_outreach/files/global_grav.kmz

USGS. Earthquake Catalog. URL: https://earthquake. usgs.gov/earthquakes/search/

USGS. Tectonic Plate Boundaries. URL: https://earthquake.usgs.gov/learn/kml.php 